\title{
A historical overview of childhood asthma in southern Africa: Are we there yet?
}

\author{
R E M Mphahlele, MB ChB, DCH (SA), Dip HIV Man (SA), Dip Allerg (SA), M Med Sci, OrcID 0000-0002-3348-9004; \\ R Masekela, $\mathrm{PhD}$
}

Department of Paediatrics and Child Health, School of Clinical Medicine, College of Health Sciences, University of KwaZulu-Natal, Durban, South Africa

Corresponding author: $R$ Mphahlele (mphahleler@ukzn.ac.za)

\begin{abstract}
Background. The prevalence of asthma, the most common respiratory disease in children, has increased in many low- and middle-income countries (LMICs), particularly in Africa. Despite poor infrastructure and limited resources, researchers in southern Africa have sought to determine the prevalence of childhood asthma, with variable results reflecting actual differences as much as methodological limitations and biases.

Objective. To collate and report findings from studies on the epidemiology of childhood asthma in southern Africa.

Method. A review of the literature was undertaken.

Results. The prevalence of childhood asthma in southern Africa is variable but has increased over the last four decades, particularly in South Africa (3.17\% to $21.29 \%$ ). Methods used to assess the burden of asthma have been in the form of questionnaires, bronchial hypersensitivity provocation tests, lung function measurement and fractional exhaled nitric oxide (FENO).

Conclusion. The prevalence of childhood asthma is increasing in rural and urban areas in southern Africa. Research collaboration driven by a better understanding of the heterogeneous nature of asthma can improve challenges faced in evaluating the burden of asthma in African countries.
\end{abstract}

Keywords. epidemiology; asthma prevalence; paediatrics.

Afr J Thoracic Crit Care Med 2021;27(4):163-167. https://doi.org/10.7196/AJTCCM.2021.v27i4.172

Asthma is characterised by chronic airway inflammation, variable airway obstruction and bronchial hyperresponsiveness (BHR) ${ }^{[1]}$ It has been generally accepted that respiratory allergic diseases were rare in Africa, particularly among rural black Africans, to such an extent that terms to describe allergic conditions are relatively new. Poor research infrastructure, and lack of diagnosis and access to healthcare, remain challenges in Africa that impact on our understanding of the burden of asthma in low- to middle-income countries (LMICs). To date, despite the knowledge that asthma is the most common non-communicable respiratory condition in children, many countries in Africa have no guidelines on diagnosis and management of asthma, and research in this field is still lacking.

Epidemiological studies that measure asthma characteristics, particularly BHR, have been most preferred when assessing asthma prevalence in South Africa (SA). ${ }^{[2-7]}$ Unfortunately, BHR is not sensitive and lacks concurrent measurement of airway inflammation, a major feature of asthma. Symptom questionnaires have better sensitivity and are therefore the method of choice when a study aims to compare differences in prevalence of asthma between populations. In contrast, BHR, with better specificity, is most appropriate to explore reasons for the differences in asthma prevalence. ${ }^{[8]}$

One of the first prevalence studies on asthma in Africa was a questionnaire-based study performed in Rhodesia (now Zimbabwe) in 1975, where symptoms were assessed in 9287 participants older than 5 years. ${ }^{[9]}$ Asthma prevalence of $1.6 \%$ in adults was similar to that of high-income countries (HICs) but was lower in children and adolescents $<20$ years, at $1.2 \%$. The authors hypothesised that the relative rarity of childhood asthma was due to a protective effect by parasitic infestation. Prior to this study, Wesley et al. ${ }^{[10]}$ described a cohort of black African children admitted with bronchospasm and found that this was more likely due to pulmonary infections when compared with white and Indian children who had a history of previous wheeze and family history of asthma.The admission rate for asthma among black children during a 5-year period (1963 1967) was $0.02 \%$ when compared with $0.79 \%$ and $0.77 \%$ for white and Indian children over the same period, respectively. The authors proposed that even though asthma was rare in black African children, more would present with asthma and allergic disease similarly to their white and Indian counterparts as they became more exposed to similar socioeconomic environments. In 1979, using exercise-induced BHR, van Niekerk et al..$^{[2]}$ demonstrated a rural-urban divide between 1375 children of the same ethnic background living in rural Transkei and urban Gugulethu, Cape Town. Of the 23 (1.67 \%) children who had exercise-induced bronchoconstriction (EIB), only one child resided in the rural area, reflecting a 20-times difference in asthma prevalence in urban $(3.17 \%)$ compared with rural children $(0.14 \%)$. It is thought that the findings were most likely due to differences in environmental exposures as these children had a similar genetic background.

More than a decade later, in the 1990s, the rural-urban difference was still evident in Zimbabwe, where reversible airways obstruction was found in urban (5.8\%), rural-urban $(3.1 \%)$ and rural $(0.1 \%)$ children. ${ }^{[11]}$ The prevalence of asthma was found to be similar in white $(5.3 \%$ 


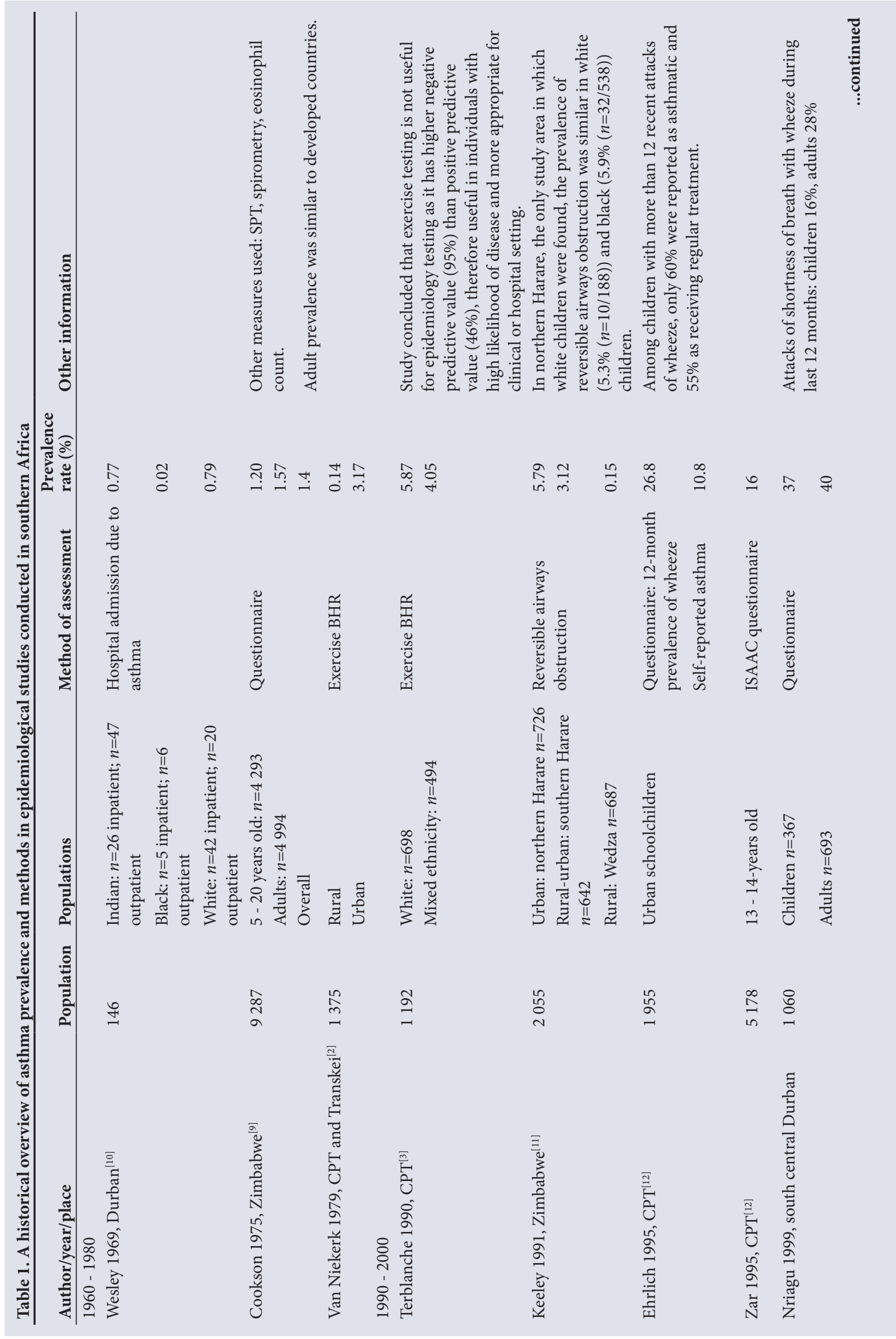




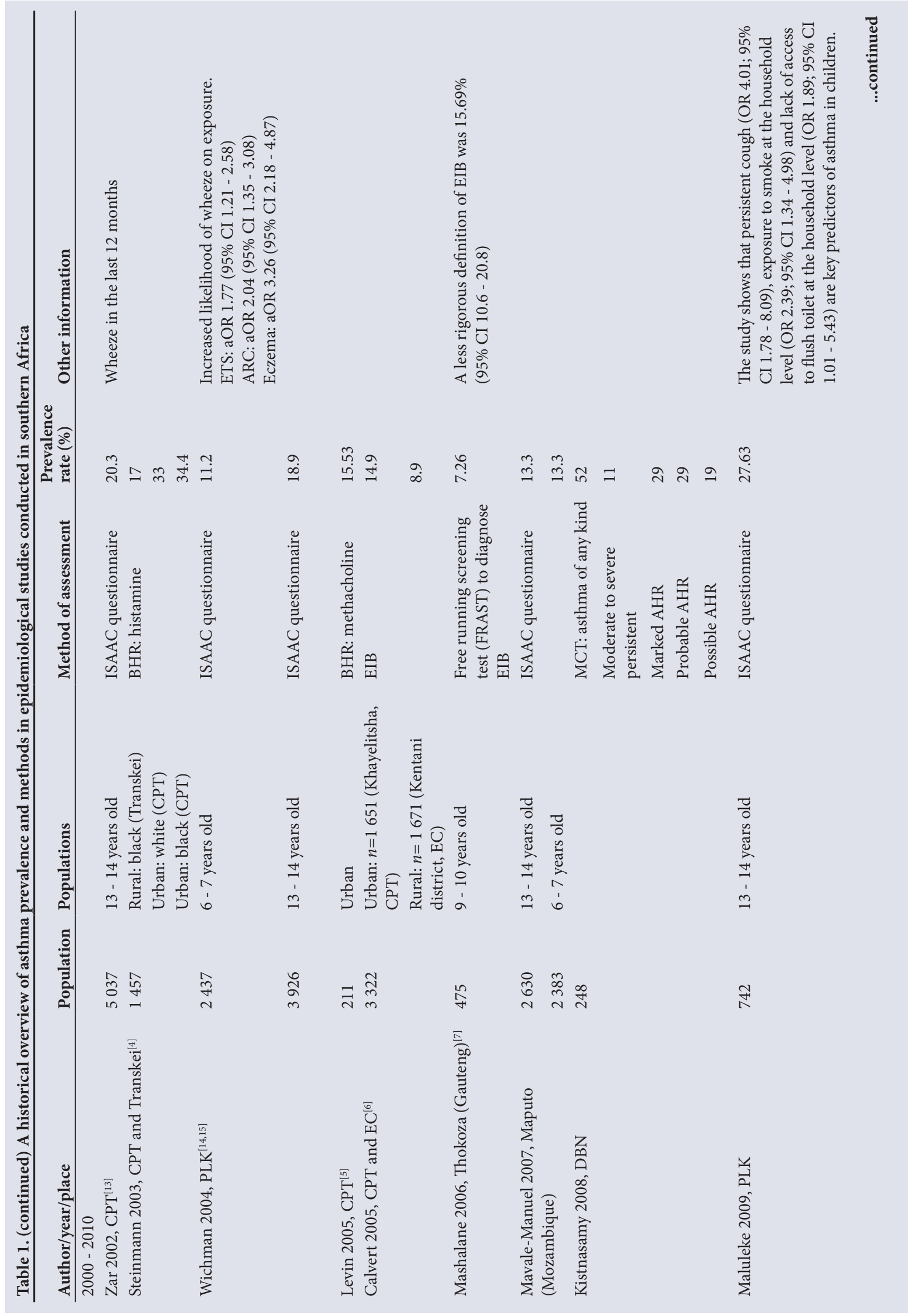




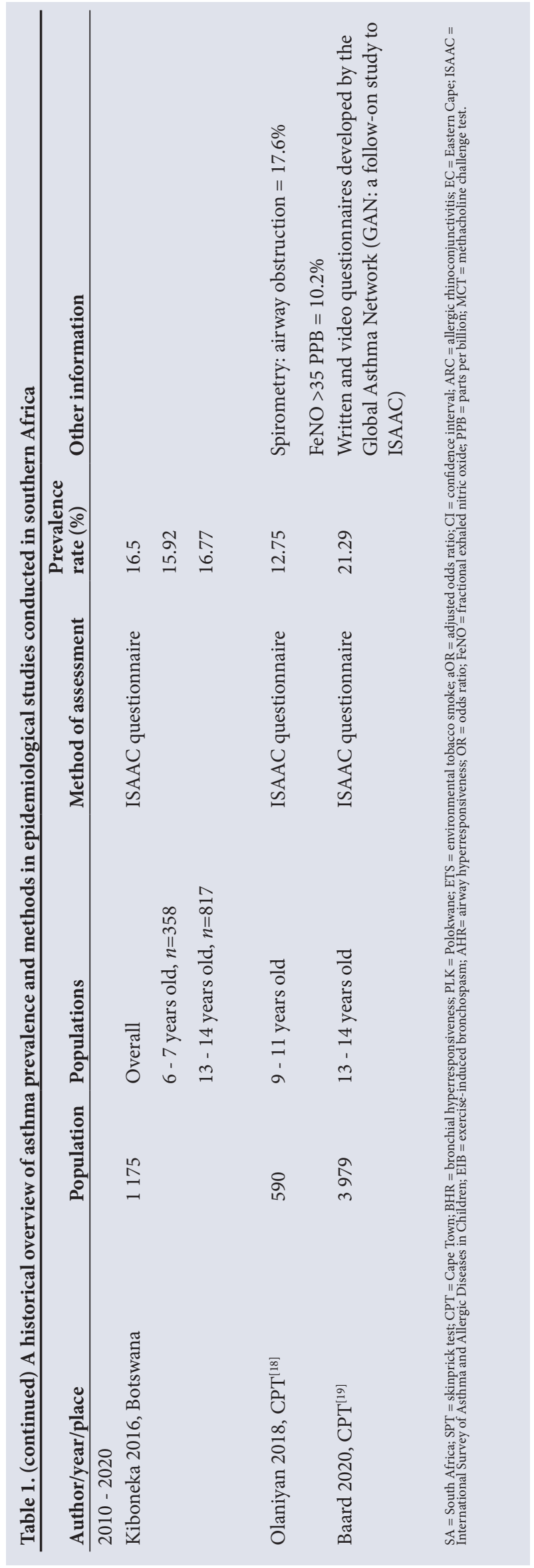

$(n=10 / 188))$ and black $(5.9 \% ; n=32 / 538))$ children who resided in a high socio-economic area in Zimbabwe. In contrast, a cohort of 1192 children in Cape Town demonstrated a difference in EIB prevalence among white $(5.9 \%)$ and mixed-ethnicity $(4.1 \%)$ school-going children living in the same urban area. ${ }^{[3]}$ This prevalence was reversed in younger mixed-ethnicity children who had a 6-times higher EIB rate. The authors suggested that early school drop-out of asthmatic mixed-ethnicity children may explain the higher prevalence of EIB in the 6 - 9-year-old group compared with older children, indicating the poor outcomes of uncontrolled asthma in this group. Additionally, the consequences of lack of diagnosis in mixed-ethnicity children indicated by history of asthma diagnosis (20.0\%) compared with white children (35.4\%) were reflected by hospital data indicating that more mixed-ethnicity children were being treated for uncontrolled asthma than white children ${ }^{[3]}$ Similarly, a lack of asthma diagnosis and access to treatment was reported in a study of parents of 1955 Cape Town children where, among children with more than 12 recent attacks of wheeze, $40 \%$ had never been diagnosed with asthma, and $45 \%$ were not receiving regular treatment. ${ }^{[12]}$

The importance of comparability and generalisability in evaluating changing trends in the prevalence of asthma and allergic disease became apparent in the late 1990s and early 2000s. The International Study of Asthma and Allergies (ISAAC) provided a globally reproducible and reliable method that has since been used to map and compare allergic diseases in children and adolescents in LMICs and HICs. Using standard written and video questionnaires, the prevalence of asthma in adolescents (13 - 14 years old) and children (6 - 7 years old) has been assessed across the globe. Using the ISAAC methodology, the prevalence of asthma in a Cape Town adolescent population was assessed and found to have increased over time (16\% - 23\% from 1995 to 2002). ${ }^{[13]}$ Alarmingly, asthma severity and the lack of diagnosis rate had also increased. At this stage, reasons for increasing asthma prevalence, particularly environmental pollution, were beginning to be interrogated. Although more rural, a concurrent Polokwane cohort showed a prevalence rate of $18 \%$ in the 13 - 14-year-old age group. ${ }^{[14]}$ The younger cohort of children (6 - 7 years) showed a 12-month prevalence rate of wheeze and severe wheeze of $11.2 \%$ and $5.7 \%$, respectively. ${ }^{[15]}$ Associated risk factors included exposure to tobacco smoke, eczema and rhinoconjunctivitis, which increased the likelihood of asthma by $1.77,2.04$ and 3.26 times, respectively. Importantly, living in a rural area significantly decreased the likelihood of wheeze by $31 \% .{ }^{[15]}$

In the context of environmental exposure, another study conducted in a highly polluted factory district in Durban on self-reported wheeze in children and adults found a prevalence of $37 \%$ and $40 \%$, respectively. ${ }^{[16]}$ Similarly, only a quarter of the children had ever had an asthma diagnosis or were on asthma treatment. In Polokwane, where the prevalence of asthma in 13 - 14-year-old adolescents was $27.6 \%$, those from a poor background or exposed to smoke in the household were twice as likely to have asthma. ${ }^{[17]}$

Over this period and into the late 2000s, BHR testing remained widely used, as it was cost-effective, a better proxy for asthma diagnosis and not prone to recall bias and language difficulties. Such studies persistently show higher asthma prevalence in urban areas, and a reducing urban-rural gradient as asthma prevalence in rural children increased. ${ }^{[4-6]}$ Follow-on studies continued to confirm an increasing 
trend in asthma prevalence coupled with risk factors such as obesity and increasing allergen sensitisation. ${ }^{[5,6]}$ Most recently, a more appropriate and complementary combination of symptom questionnaires and BHR has been used in epidemiological studies.

As asthma understanding and availability of resources improve, a judicious combination of methodologies considering the heterogeneous nature of asthma is expected in clinical practice and research. A small but increasing number of studies are beginning to incorporate symptomatology, environmental questions and measures of lung function, airway inflammation and atopy. One such study conducted in 2017 in 590 children aged 9 - 11 years assessed ambient air pollution exposure and its role in asthma prevalence and induction. The ISAAC questionnaire was administered to caregivers, and pulmonary assessment included spirometry and fractional nitric oxide (FeNO), and aeroallergen sensitisation was measured using the Phadiatop test (Phadia AB, Sweden). ${ }^{[18]}$ The prevalence of doctor-diagnosed asthma was $3.4 \%$, with only half on treatment, while a much higher prevalence of asthma was identified by symptoms (12.9\%), airway obstruction (17.6\%) and airway inflammation (10.2\%). Associated risk factors for wheeze were dampness (odds ratio (OR) 2.60; 95\% confidence interval (CI) 1.18 - 5.71) and environmental tobacco smoke (OR 1.79; 95\% CI 1.02 - 3.15). Much has been elucidated by preceding prevalence studies, but the extent to which severe asthma and poor asthma control affect children remains largely unknown. The Global Asthma Network (GAN) Phase I, a follow-up of the ISAAC study, is the latest in developments defining asthma and allergy prevalence worldwide. Time trend analysis of these data in Cape Town shows a stabilisation in asthma prevalence in 2017 but, disappointingly, asthmatic children are not diagnosed and suffer severe symptoms. ${ }^{[19]}$ While the use of a combination of methods to assess asthma holistically in research is an exciting new development on asthma epidemiology, this requires more resources that are often lacking in LMICs. For this reason, a collaborative observational study of children's lung health in sub-Saharan Africa, under way since 2019, plans to report on the burden of asthma and asthma risk factors through symptom and control questionnaires, spirometry and FeNO in adolescents. ${ }^{[20]}$

Table 1 provides aa historical overview of asthma prevalence and methods in epidemiological studies conducted in southern Africa.

Improvement in research infrastructure through international and national collaboration coupled with a new and better understanding of asthma can improve the rate of asthma diagnosis and quantification of its burden in African countries.

\section{Declaration. None.}

Acknowledgements. None.

Author contributions. Equal contributions.

Funding. None.

Conflicts of interest. None.
1. Bousquet J, Jeffery PK, Busse WW, et al. Asthma: From bronchoconstriction to airways inflammation and remodeling. Am J Respir Crit Care Med 2000;161(5):1720-1745.

2. Van Niekerk C, Weinberg E, Shore S, Heese HdV, van Schalkwyk D. Prevalence of asthma: A comparative study of urban and rural Xhosa children. Clin Exp Allergy 1979;9(4):319-324. https://doi.org/10.1111/j.1365-2222.1979.tb02489.x

3. Terblanche E, Stewart R. The prevalence of exercise-induced bronchoconstriction in Cape Town schoolchildren. S Afr Med J 1990;78:744-747.

4. Steinman HA, Donson H, Kawalski M, Toerien A, Potter PC. Bronchial hyperresponsiveness and atopy in urban, peri-urban and rural South African children. Pediatr Allergy Immunol 2003;14(5):383-393. https://doi.org/10.1034/j.13993038.2003.00062.x

5. Levin M, Muloiwa R, Motala C. Associations between asthma and bronchial hyperresponsiveness with allergy and atopy phenotypes in urban black South African teenagers. S Afr Med J 2011;101(7):472-476. https://doi.org/10.1186/1939-4551-6s1-p39

6. Calvert J, Burney P. Effect of body mass on exercise-induced bronchospasm and atopy in African children. J Allergy Clin Immunol 2005;116(4):773-779. https://doi. org/10.1016/j.jaci.2005.05.025

7. Mashalane M, Stewart A, Feldman C, et al. Prevalence of exercise-induced bronchospasm in Thokoza schoolchildren. S Afr Med J 2006;96(1):67-70.

8. Pekkanen J, Pearce N. Defining asthma in epidemiological studies. Eur Respir J 1999;14(4):951-957. https://doi.org/10.1034/j.1399-3003.1999.14d37.x

9. Cookson J, Makoni G. Prevalence of asthma in Rhodesian Africans. Thorax 1980;35(11):833-837. https://doi.org/10.1136/thx.35.11.833

10. Wesley AG, Clyde JH, Wallace HL. Asthma in Durban children of three racial groups. S Afr Med J 1969;43(4):87-89.

11. Keeley D, Neill P, Gallivan S. Comparison of the prevalence of reversible airways obstruction in rural and urban Zimbabwean children. Thorax 1991;46(8):549-553. https://doi.org/10.1136/thx.46.8.549

12. Ehrlich R, du Toit D, Jordaan E, Volmink J, Weinberg E, Zwarenstein M. Prevalence and reliability of asthma symptoms in primary school children in Cape Town. Int J Epidemiol 1995;24(6):1138-1146. https://doi.org/10.1093/ije/24.6.1138

13. Zar HJ, Ehrlich RI, Workman L, et al. The changing prevalence of asthma, allergic rhinitis and atopic eczema in African adolescents from 1995 to 2002. Pediatr Allergy Immunol 2007;18(7):560-565.

14. Wichmann J, Wolvaardt JE, Maritz C, et al. Household conditions, eczema symptoms and rhinitis symptoms: Relationship with wheeze and severe wheeze in adolescents living in the Polokwane area, South Africa. J Asthma 2007;44(8):659-666. https://doi. org $/ 10.1080 / 02770900701555000$

15. Wichmann J, Wolvaardt JE, Maritz C, et al. Household conditions, eczema symptoms and rhinitis symptoms: Relationship with wheeze and severe wheeze in children living in the Polokwane area, South Africa. Matern Child Health J 2009;13(1):107118. https://doi.org/10.1007/s10995-007-0309-x

16. Nriagu J, Robins T, Gary L, et al. Prevalence of asthma and respiratory symptoms in south-central Durban, South Africa. Eur J Epidemiol 1999;15(8):747-755. https://doi. org/10.1023/a:1007653709188

17. Maluleke KR, Worku Z. Environmental determinants of asthma among school children aged 13-14 in and around Polokwane, Limpopo Province, South Africa. Int J Environ Res Public Health 2009;6(9):2354-2374. https://doi.org/10.3390/ ijerph6092354

18. Olaniyan T, Dalvie MA, Röösli M, et al. Asthma-related outcomes associated with indoor air pollutants among schoolchildren from four informal settlements in two municipalities in the Western Cape Province of South Africa. Indoor Air 2019;29(1):89-100. https://doi.org/10.1111/ina.12511

19. Baard CB, Franckling-Smith Z, Munro J, Workman L, Zar HJ. Asthma in South African adolescents: A time trend and risk factor analysis over two decades. ERJ Open Res 2021;7(2):00576-2020. https://doi.org/10.1183/23120541.00576-2020

20. Mosler G, Oyenuga V, Addo-Yobo E, et al. Achieving control of asthma in children in Africa (ACACIA): Protocol of an observational study of children's lung health in six sub-Saharan African countries. BMJ Open 2020;10(3):e035885. https://doi. org/10.1136/bmjopen-2019-035885

Accepted 25 October 2021. 